\title{
Growth and Physiological Responses to Drought Stress in Four Oleander Clones
}

\author{
Genhua Niu² and Denise S. Rodriguez \\ Department of Horticultural Sciences, Texas A\&M University, El Paso Agricultural Research \\ and Extension Center, El Paso, TX 79927 \\ Wayne Mackay ${ }^{1}$ \\ Department of Horticultural Science, Texas A\&M University, Dallas Agricultural Research \\ and Extension Center, Dallas, TX 75252
}

\begin{abstract}
Additional INDEX wORDs. chlorophyll fluorescence, gas exchange, Nerium oleander, water relation
Abstract. Oleander (Nerium oleander L.), native to southern Asia and the Mediterranean region, is a fast-growing evergreen shrub planted widely in the southern United States. A greenhouse study was conducted to quantify the growth and physiological responses of two cultivars, Hardy Pink and Hardy Red, and two breeding lines, EP1 and EP2, of oleander to a 12-week cyclic drought stress. Drought stress was imposed by irrigating the plants to near container capacity and then withholding irrigation until predetermined container weights were reached. Compared with the control where plants were well-irrigated throughout the experiment, shoot dry weight (DW) was reduced by $52 \%, 41 \%, 34 \%$, and $11 \%$ in EP1, EP2, 'Hardy Red', and 'Hardy Pink', respectively. Root-to-shoot DW ratio was higher for the drought-treated plants than the control, regardless of cultivar or breeding line (hereafter, clone). The increase in root-to-shoot DW ratio from the drought treatment was highest in EP1, followed by EP2, 'Hardy Pink', and 'Hardy Red.' New shoot growth was greatest in 'Hardy Pink', followed by 'Hardy Red', EP1, and EP2. The number of newly developed shoots during the drought treatment period was 6.8, 3.0, 0.7, and 0.0 in 'Hardy Pink', 'Hardy Red', EP1, and EP2, respectively. As substrate volumetric moisture content decreased from $30 \%$, leaf net photosynthetic rate $\left(P_{n}\right)$, evapotranspiration rate $(E)$, and stomatal conductance $\left(g_{s}\right)$ decreased in all clones. A curvilinear relationship between $P_{n}$ and $g_{s}$ was found in all clones. EP1 had a lower maximum $P_{n}\left(P_{m}\right)$ than those of 'Hardy Pink' and EP2 but was not different from that of 'Hardy Red'. Predawn leaf water potential began to decrease rapidly when substrate moisture content dropped below $15 \%$ in all clones. During the dry-down, compared with the control, increases in minimal fluorescence $\left(F_{0}\right)$ or decreases in maximal fluorescence $\left(F_{m}\right)$ and $F_{v} / F_{m}\left(F_{v}=F_{m}-F_{0}\right)$ in drought-stressed plants were observed in all clones, indicating some damage in photosystem II from the drought treatment. However, compared with growth parameters, the differences in physiological responses to drought stress among the clones were much smaller. 'Hardy Pink' was more tolerant to drought stress than 'Hardy Red' and the other two clones in terms of productivity because it maintained greatest growth during the drought-stress period. However, EP2 and EP1 may be more tolerant if survival is concerned because they had a higher root-to-shoot DW ratio with minimal new growth.
\end{abstract}

Drought is one of the critical environmental stresses that affect the establishment, survival, growth, and performance of shrubs and trees in urban and suburban landscape environments (Cregg, 2004; Fernández et al., 2006). Watering restrictions, which are becoming more common in many parts of the world, exacerbate the effect of drought stress on the establishment and survival of these plants. One strategy to improve the landscape may be the selection of drought-tolerant plants.

Plants express various responses to drought stress and develop a wide range of mechanisms from morphological to physiological aspects. For example, the smaller, thicker leaves with thicker cuticles, more cuticular wax, and a higher specific leaf mass in Mexican redbud [Cercis canadensis L. var. mexicana (Rose) M. Hopk.] contribute to water-conserving capability and survival in arid and semiarid regions compared

Received for publication 24 Aug. 2007. Accepted for publication 8 Jan. 2008. We gratefully acknowledge financial support from the Cooperative State Research, Education and Extension Service, the U.S. Department of Agriculture under Agreement No. 2005-34461-15661, El Paso Water Utilities, and Texas Agricultural Experiment Station.

${ }^{1}$ Current address: Mid-Florida Research \& Education Center, University of Florida IFAS, 2725 South Binion Road, Apopka, FL 32703-8504.

${ }^{2}$ Corresponding author. E-mail: gniu@ag.tamu.edu. with eastern redbud (C. Canadensis; Tipton and White, 1995). When plants are under drought-stressed conditions, relative water content, water potential, and turgor of cells decrease and the concentration of ions and other solutes in the cells increase, thereby decreasing the osmotic adjustment (Tezara et al., 1999). However, in a study by Björkman et al. (1980), there was no osmotic adjustment in oleander (Nerium oleander L.) plants under drought-stressed conditions.

Photosynthesis is the primary process for plant biomass production and is one of the physiological processes most sensitive to environmental stresses (Hsiao and Acevedo, 1974; Huang, 2004). Consequently, the ability to maintain a reasonable rate of photosynthesis under stressful conditions can be a good indicator of a plant's adaptability. A drought-resistant cultivar Koroneiki of olive (Olea europea L.) performed better and was able to maintain higher leaf photosynthetic rate under high air vapor pressure deficit compared with other green olive cultivars (Hagidimitriou and Pontikis, 2005).

Chlorophyll fluorescence has been routinely used to detect and quantify the tolerance of plants to various stresses (Percival and Sheriffs, 2002; Willits and Peet, 2001). However, the effect of drought stress on chlorophyll fluorescence values is contradictory, possibly because of differences in the severity of 

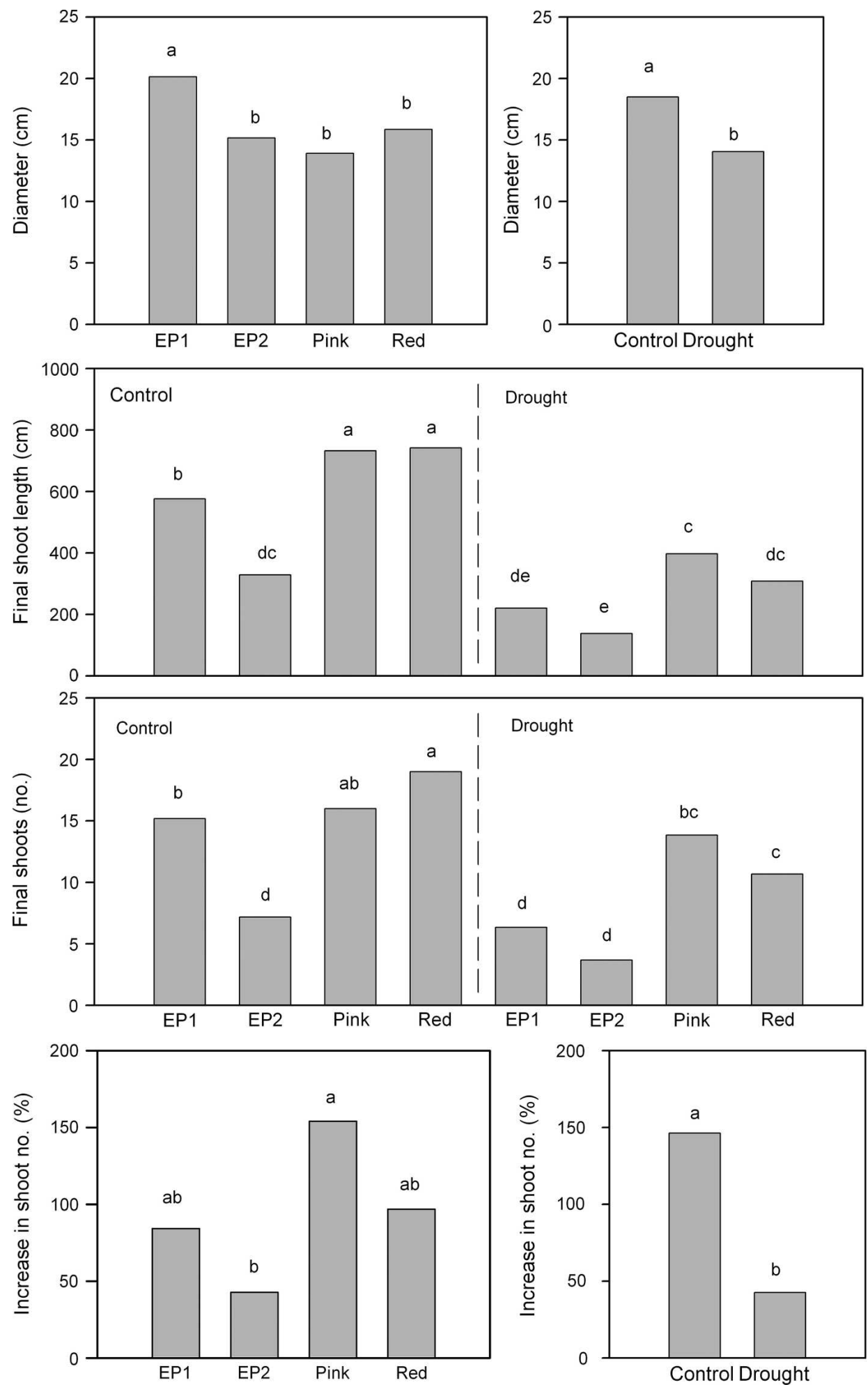

Fig. 1. Effects of drought treatment and clone on main stem diameter, total shoot length and number, and increase in shoot number [(final shoot no. - initial shoot no.)/initial shoot no. $\times 100 \%$ ] in EP1, EP2, 'Hardy Pink' (Pink), and 'Hardy Red' (Red) of Nerium oleander. Means followed by the same letters are not significantly different among the clones or treatment tested by Student-Newman-Keuls multiple comparison at $P=0.05(\mathrm{n}=6)$.

herbaceous plants (Starman and Lombardini, 2006) were not influenced by drought stress. However, $\mathrm{F}_{0}$ of banana (Musa L.) leaves increased and $\mathrm{F}_{\mathrm{m}}$ decreased under drought stress (Thomas and Turner, 2001).

Variations exist in characteristics of drought tolerance among cultivars (Zwack and Graves, 1998), seed sources (Cregg and Zhang, 2001), and provenance (Bsoul et al., 2006; St. Hilaire and Graves, 2001). These variations in response to stress among genotypes offer opportunities for selecting plants with optimal characteristics for high rates of photosynthesis and productivity. For example, by characterizing the gas exchange in response to temperature among genotypes and provenance, heat tolerant genotypes and cultivars have been selected for holly (Ilex L.; Ranney and Ruter, 1997), rhododendron (Rhododendron hyperythrum Hayata; Ranney et al., 1995), and raspberry (Rubus idaeus L.; Stafne et al., 2000). It is generally considered that genotypes originating from xeric environments can tolerate drought stress better than those from mesic environments. St. Hilaire and Graves (2001) concluded that maple (Acer L.) taxa from more xeric provenances are more likely to perform better in arid environments than trees from mesic environments. In addition, seedlings of Pinus sylvestris L. from drier central Asian seed sources survived drought stress longer than seedlings from more mesic European and coastal seed sources (Cregg and Zhang, 2001). However, Cregg (1994) found that seedling survival of Pinus ponderosa Dougl. ex Laws. to drought stress was poorly correlated to climate indices of the seed sources.

Oleander, native to southern Asia and the Mediterranean region (Dirr, 1998), is a fast-growing, tough, versatile evergreen shrub that can reach up to $6 \mathrm{~m}$ tall but is usually trimmed at 2 to $3 \mathrm{~m}$ to form a round shrub. It grows well in warm subtropical regions and is commonly used as an ornamental plant in landscapes, parks, and along roadsides. About

drought stress and species. For example, chlorophyll fluorescence values of field-grown papaya (Carica papaya L.; Marler and Mickelbart, 1998), bigtooth maple (Acer grandidentatum Nutt.; Bsoul et al., 2006), and a number of greenhouse-grown
400 cultivars have been named, representing a wide variety of flower colors (Mackay et al., 2005). Early work illustrated, although no information on cultivar was given, that leaf gas exchange of oleander decreased as soil moisture content 
Table 1. A summary of analysis of variance on the effects of drought treatment (Trt), clone (EP1, EP2, 'Hardy Pink', and 'Hardy Red'), and the interaction of Trt and clone on main shoot diameter, total shoot length and shoot number (no.), shoot dry weight (DW), root DW, total DW, root-to-shoot ratio, leaf area (LA), SLM, leaf width (Width), and length (Length) at the end of experiment of four Nerium oleander clones that were grown in the greenhouse under well-irrigated or drought-stressed conditions.

\begin{tabular}{|c|c|c|c|c|c|c|c|c|c|c|c|}
\hline \multirow[b]{2}{*}{ Source } & \multicolumn{11}{|c|}{ Analysis of variance } \\
\hline & Diameter & $\begin{array}{l}\text { Shoot } \\
\text { length }\end{array}$ & $\begin{array}{c}\text { Shoot } \\
\text { no. }\end{array}$ & $\begin{array}{c}\text { Shoot } \\
\text { DW }\end{array}$ & $\begin{array}{l}\text { Total } \\
\text { DW }\end{array}$ & $\begin{array}{l}\text { Root } \\
\text { DW }\end{array}$ & Root/Shoot & LA & SLM & Width & Length \\
\hline Trt & $* * *$ & $* * *$ & $* * *$ & $* * *$ & $* * *$ & NS & $* * *$ & $* * *$ & $* * *$ & $* * *$ & $* * *$ \\
\hline Clone & $* * *$ & $* * *$ & $* * *$ & $* * *$ & $* * *$ & $* * *$ & $* * *$ & $* * *$ & $* * *$ & $* * *$ & $* * *$ \\
\hline Trt $\times$ Clone & NS & $*$ & $*$ & $* * *$ & $* *$ & NS & NS & $* * *$ & $*$ & NS & NS \\
\hline
\end{tabular}

$\overline{\mathrm{NS}}, *, * *, * * *$ Nonsignificant or significant at $P<0.05,0.01$, or 0.001 , respectively.

decreased (Björkman et al., 1980). However, no relationship was found between leaf water potential and leaf stomatal conductance $\left(g_{\mathrm{S}}\right)$ for oleander (Gollan et al., 1985).

Two representative commercial cultivars, Hardy Pink and Hardy Red, and two breeding lines, EP1 and EP2, were selected for this study. EP1 and EP2 were selected because these plants were still alive despite not being irrigated for $\approx 8$ years in a semiarid climate. Thus, this study was undertaken to compare the growth, photosynthetic characteristics, and leaf water relations of two breeding lines with two commercial cultivars in response to drought stress.

\section{Materials and Methods}

Plant materials and culture conditions. Vegetative cuttings of two breeding lines, EP1 and EP2, of oleander were taken in July 2005 from the shrubs in the field that were planted in 1992 at the Texas A\&M Research and Extension Center at El Paso and had received no supplemental irrigation since 1997. EP1 and EP2 were derived from open pollinations with 'Franklin Roosevelt' as the female parent. Cuttings of two commercial cultivars, Hardy Pink and Hardy Red, were taken the next week from stock plants maintained at the Texas A\&M Research and Extension Center at Dallas. All cuttings were treated with naphthaleneacetic acid (NAA) at $2000 \mathrm{mg} \cdot \mathrm{L}^{-1}$ and were rooted in a 1:1 (by volume) mix of perlite and vermiculite. Rooted cuttings were transplanted on 17 Aug. 2005 to $1.8-\mathrm{L}$ round plastic pots filled with a 1:1 potting mix of Sunshine Mix No. 4 (SunGro Horticulture, Bellevue, WA) and composted mulch (Western Organics, Tempe, AZ) amended with $5 \mathrm{~kg} \cdot \mathrm{m}^{-3}$ dolomite limestone (Carl Pool Earth-Safe Organics, Gladewater, TX) and $1 \mathrm{~kg} \cdot \mathrm{m}^{-3}$ Micromax (Scott, Marysville, OH). The plants were transplanted again on 2 Feb. 2006 into 12-L plastic pots filled with the same substrate. Greenhouse temperatures were controlled by a pad-and-fan cooling system during the summer months and a natural gas heating system during the winter months. Plants were irrigated whenever the substrate started to dry with a nutrient solution containing $0.5 \mathrm{~g} \cdot \mathrm{L}^{-1}$ of 20N-8.6P-16.7K (Peters 20-20-20; J.R. Peters, Allentown, PA). The average actual greenhouse environmental conditions during the experimental period were maintained as follows: day temperature at $27{ }^{\circ} \mathrm{C} \pm 3{ }^{\circ} \mathrm{C}$ and night at $20^{\circ} \mathrm{C} \pm 2{ }^{\circ} \mathrm{C}$; day relative humidity at $40 \% \pm 5 \%$ and night at $70 \% \pm 5 \%$; and daily light integral $(P A R)$ was $13 \pm 2 \mathrm{~mol} \cdot \mathrm{m}^{-2} \cdot \mathrm{d}^{-1}$. The temperatures were measured by thermocouples (copper and constantan) and photosynthetic photon flux $(P P F)$ was measured by a quantum sensor (model QSO-SUN; Apogee Instruments, Logan, UT) every $10 \mathrm{~s}$; the hourly averages were recorded by a $21 \mathrm{X}$ datalogger (Campbell Scientific, Logan, UT).
Mild Drought treatment. The drought experiment was initiated on 22 June 2006 and ended on 18 Sept. 2006. Uniform plants from each clone (cultivar or breeding line) were selected and divided into two groups: drought or control. Each group had six plants per clone. The experiment was a split-plot design with drought as the main plot and four clones the subplot. Flowers were removed from the shoots (for 'Hardy Pink' and 'Hardy Red'; the other two had no flowers) at the beginning of the experiment. Mild drought stress was created by withholding irrigation until a predetermined container weight was reached. This mild drought stress was determined on extra plants by measuring the predawn water potential (approximately -1.3 $\mathrm{MPa}$ ) and weighing the container. On the same day, visual appearance was examined to make sure that plants exhibited mild wilting at midday. All plants were weighed daily and irrigated individually whenever the target weights were reached because plants, even in the same treatment, reached their target weights on different days. Also, the increase in plant growth over time was considered during the experimental period in determining the target weights $(\approx 200 \mathrm{~g}$ in fresh weight gain for the whole experimental period on average across clones in the drought treatment). The container capacity (maximum weight, including the plant, after substrate is saturated with water) was 7.0 to $7.4 \mathrm{~kg}$, depending on clone. The initial substrate water holding capacity was $42 \%$ (volumetric) or $58 \%$ (gravimetric). The control plants were well watered throughout the experimental period, which corresponded to substrate volumetric moisture contents at $\approx 30 \%$ at re-irrigation.

SEVERE DROUght TREATMENT. All plants in the mild drought treatment were exposed to a severe drought stress before the end of the experiment, which was initiated on 6 Sept. 2006 and ended when severe drought stress was reached (severe wilting with predawn water potential of approximately $-2.0 \mathrm{MPa}$ or lower). During the dry-down, predawn water potential, gas exchange, container weight (for later calculation of substrate moisture contents), chlorophyll fluorescence, and relative chlorophyll content were measured. Details of these measurements are described below.

Growth DETERMinATION. Main stem diameter $(10 \mathrm{~cm}$ above the substrate surface), shoot number, and total length of all shoots per plant were recorded at the beginning and at the end of the experiment. Plants were destructively harvested at the end of the experiment. Fresh weights of shoots, leaves, and roots, main stem diameter, and length and width of three youngest, fully expanded leaves per plant were determined. Because the dry weight of the substrate was needed to determine the substrate moisture contents, roots were separated from the substrate within 2 weeks of the severance of stems. During the separation process, the containers with roots were stored at 

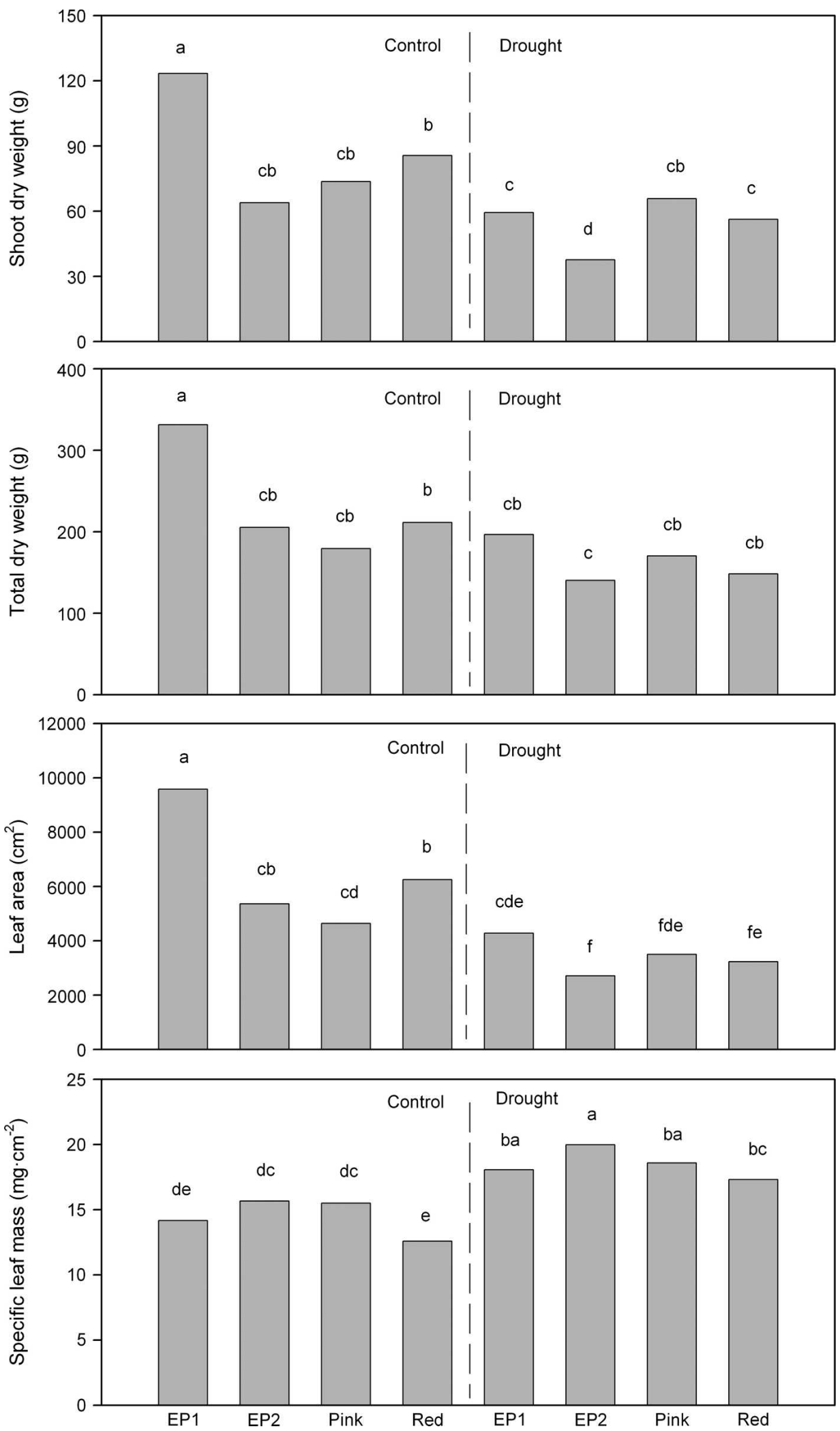

Fig. 2. Effects of drought treatment and clone on shoot and total dry weight, leaf area, and SLM of EP1, EP2, 'Hardy Pink' (Pink), and 'Hardy Red' (Red) of Nerium oleander. Means followed by the same letters are not significantly different among the clones tested by Student-Newman-Keuls multiple comparison at $P=0.05(\mathrm{n}=6)$.
$4{ }^{\circ} \mathrm{C}$. The dry weights of shoots, roots, and leaves were determined by oven drying at $70{ }^{\circ} \mathrm{C}$ to constant weight. Leaf area was measured using a leaf area meter (LI-3100; LI-COR, Lincoln, NE). Specific leaf mass (SLM) was calculated by dividing the leaf dry weight by the leaf area.

SuBSTRATE MOISTURE CONTENT. The volumetric substrate moisture content was estimated as follows: [(grams fresh weight of substrate grams dry weight of substrate)/milliliter volume of substrate] $\times 100 \%$. Fresh weight of substrate $=$ total container weight - shoot fresh weight (including leaves) - container weight. Dry weight of substrate per container was determined by oven drying at $80{ }^{\circ} \mathrm{C}$ for 2 weeks after the roots were separated from the substrate. Root mass (both fresh and dry) was small enough to be neglected in the above formula compared with the bulk mass of other elements.

LEAF WATER POTENTIAL MEASUREMENT. At the beginning of the mild drought treatment, the predawn water potentials at the end of a cyclic drought cycle (predawn on the day when plants were re-irrigated) were determined on recent fully expanded leaves by using leafcutter psychrometers (J.R.D. Merrill Specialty Equipment, Logan, UT) on three plants with three subsamples. A CR7 datalogger (Campbell Scientific) was used to read the psychrometer voltage outputs after a 3-h equilibration period in a $25{ }^{\circ} \mathrm{C}$ water bath in a temperature-controlled room. During the severe drought stress cycle, predawn water potentials of three plants with three subsamples per treatment were determined using the same leaf-cutter psychrometers.

Gas EXChange MEASUREMENT. Leaf net photosynthesis, transpiration, and $g_{\mathrm{S}}$ were measured on four plants per clone daily during the severe drought treatment by placing the recently matured leaf in the cuvette of a portable gas exchange system (CIRAS-2; PP Systems, Amesbury, MA). The environmental conditions in the cuvette were controlled at leaf temperature $=25{ }^{\circ} \mathrm{C}$, $P P F=1000 \mu \mathrm{mol} \cdot \mathrm{m}^{-2} \cdot \mathrm{s}^{-1}$, and $\mathrm{CO}_{2}$ concentration $=380 \mu \mathrm{mol} \cdot \mathrm{mol}^{-1}$. Data were recorded when the environmental conditions and gas 

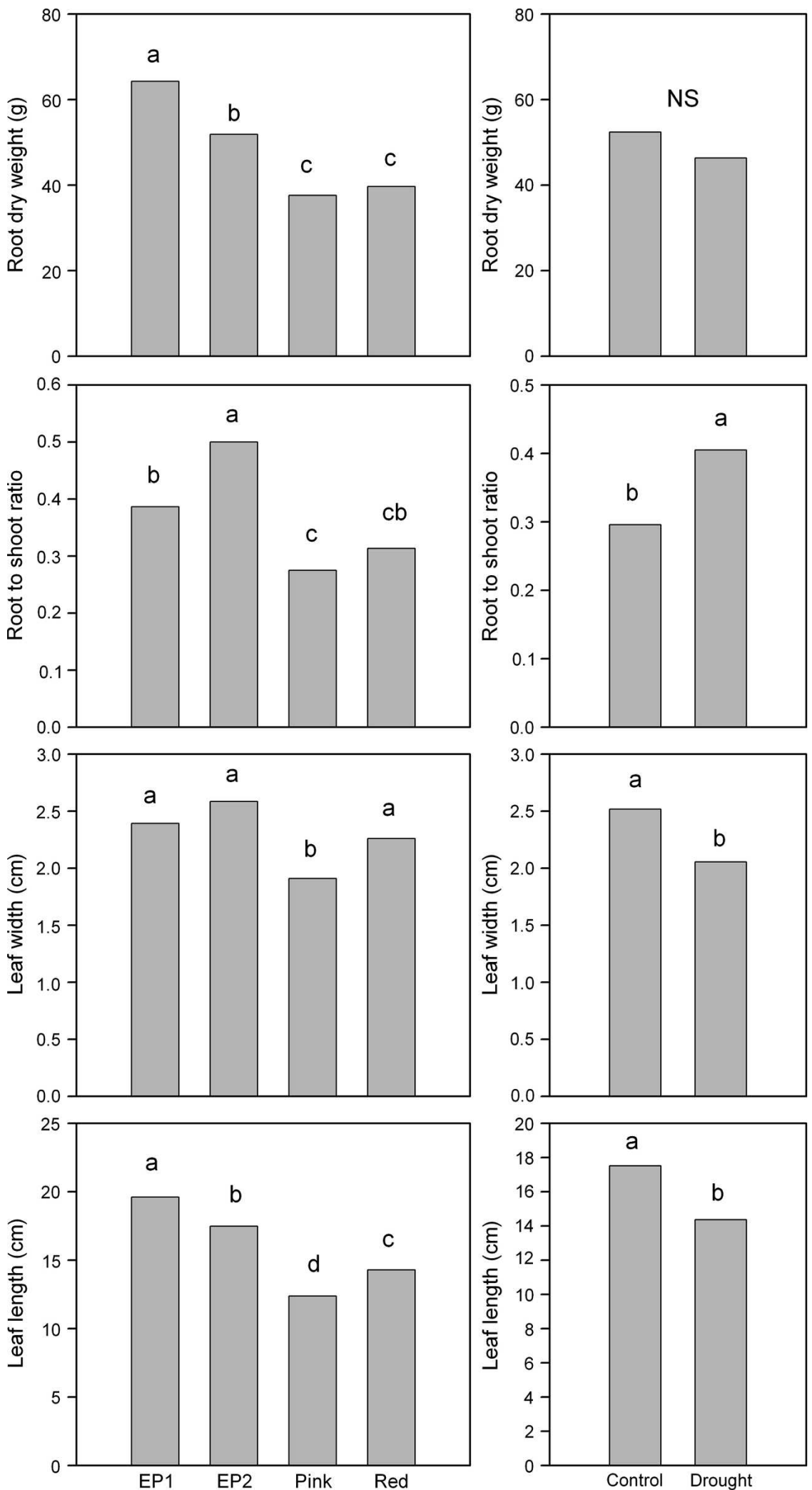

Fig. 3. Effects of drought treatment and clone on root dry weight, root to shoot ratio, leaf width, and leaf length of EP1, EP2, 'Hardy Pink' (Pink), and 'Hardy Red' (Red) of Nerium oleander. Means followed by the same letters are not significantly different among the clones or treatments tested by Student-Newman-Keuls multiple comparison at $P=0.05(\mathrm{n}=6)$. exchange parameters in the cuvette became stable. These measurements were taken between 0900 and 1200 HR. The same measurements were repeated daily on the same leaf (premarked) of the same plants.

To characterize the differences in photosynthetic characteristics among the clones, light curves were obtained by measuring the $\mathrm{P}_{\mathrm{n}}$ in response to various $P P F$ levels on three well-watered plants per clone in the control treatments. The environmental conditions in the leaf cuvette were controlled at the same levels as mentioned above, except for $P P F$. A net photosynthetic model (Niu et al., 1996) was used to fit the curves:

$\mathrm{P}_{\mathrm{n}}=\mathrm{P}_{\mathrm{m}} \cdot\left\{1-\exp \left[-\mathrm{k}_{1}\left(P P F-\mathrm{k}_{2}\right)\right]\right\}$

where $\mathrm{P}_{m}$ is the maximum $\mathrm{P}_{\mathrm{n}}$ $\left(\mu \mathrm{mol} \cdot \mathrm{m}^{-2} \cdot \mathrm{s}^{-1}\right), \mathrm{k}_{1}$ is the slope of the $\mathrm{P}_{\mathrm{n}}$ versus $P P F$ curve at the light compensation point $\left(\mu \mathrm{mol}^{-1} \cdot \mathrm{m}^{2} \cdot \mathrm{s}\right)$, and $\mathrm{k}_{2}$ is the light compensation point $\left(\mu \mathrm{mol} \cdot \mathrm{m}^{-2} \cdot \mathrm{s}^{-1}\right)$. Parameters were estimated using PROC NLIN (SAS Institute, Cary, NC). Because the response of $\mathrm{P}_{\mathrm{n}}$ to $\mathrm{g}_{\mathrm{s}}$ was similar to light curves, the same equation was used to fit the $\mathrm{P}_{\mathrm{n}}-\mathrm{g}_{\mathrm{s}}$ response curves.

Chlorophyll fluorescence. To examine the influence of progressively increased drought stress on leaf photosynthetic apparatus among the clones, leaf chlorophyll fluorescence values, $\mathrm{F}_{0}, \mathrm{~F}_{\mathrm{m}}$, and the maximal photochemical efficiency of photosystem (PS) II $\left(\mathrm{F}_{\mathrm{v}} / \mathrm{F}_{\mathrm{m}}, \mathrm{F}_{\mathrm{v}}=\right.$ $\mathrm{F}_{\mathrm{m}}-\mathrm{F}_{0}$ ) were measured during the dry-down cycle on young, fully expanded leaves at the same time every day using a Plant Efficiency Analyzer (Hansatech Instruments Ltd., Kings Lynn, UK). Before the measurement, leaves were darkadapted for $10 \mathrm{~min}$ by attaching them to the light-exclusion clips. To see if there was a midday depression in chlorophyll fluorescence values, five measurements were performed from morning (0900 HR) to later afternoon (1600 HR) on control plants on a sunny day in the middle of the experiment.

Data ANALYSIS AND STATISTICS. A two-way analysis of variance procedure was used to test the effects of drought stress and clone on plant growth and morphology. 
When differences were found, means were separated across the eight groups, four clones in the control and drought (with interaction between treatment and clone) or across the four clones and treatments (without interaction) by Student-Newman-Keuls multiple comparisons. Gas exchange parameters were plotted against substrate volumetric moisture content. Linear or quadratic regression was performed, and the significance was analyzed using PROC REG. All statistical analyses were performed using SAS (version 9.1.3; SAS Institute).

\section{Results}

GROWTH AND MORPHOLOGY. Drought stress reduced main stem growth during the experimental period, as quantified by stem diameter (Fig. 1; Table 1). There was interaction between drought treatment and clone on final shoot length and shoot number, but not on main diameter and the increase of shoot number. EP1 had the largest final diameter, but no differences were found among the other clones. Also, there were no differences in the increases in diameters and initial total shoot length among the clones (data not shown), regardless of drought treatment. 'Hardy Pink' and 'Hardy Red' in the control treatment had the greatest total shoot length, followed by EP1 in the control. EP2 in the drought had the smallest shoot length and no new shoot development. Drought stress suppressed the shoot development. There were no differences in the increase of shoot number among EP1, 'Hardy Pink', and 'Hardy Red' or among EP1, EP2, and 'Hardy Red'.

Drought treatment and clone interacted significantly on shoot dry weight (DW), total DW, leaf area, and SLM (Table 1). Shoot DW was highest in the control EP1 and was lowest in drought EP2 (Fig. 2). No differences were found among EP2, 'Hardy Pink', 'Hardy Red' in the control and 'Hardy Pink' in the drought or among EP2 and 'Hardy Pink' in the control, EP1, 'Hardy Pink', and 'Hardy Red' in the drought. Total DW was highest in EP1 in the control. 'Hardy Red' in the control had higher total DW than that of EP2 in the drought. The remaining clones had similar total DW. Drought stress reduced shoot DW by $52 \%, 41 \%, 34 \%$, and $11 \%$ in EP1, EP2, 'Hardy Red', and 'Hardy Pink', respectively, compared with the control. The order of reduction percentage in total DW was the same as that in shoot DW.

Drought stress reduced leaf area and SLM (Table 1; Fig. 2). EP1 in the control had the largest leaf area. EP2, 'Hardy Pink', and 'Hardy Red' in the drought had the smallest leaf area. However, no differences in leaf area among 'Hardy Pink' in the control, EP1, 'Hardy Pink', and 'Hardy Red' in the drought were found. Also, no differences in leaf area were observed between EP2 and 'Hardy Red' in the control or among EP2 and 'Hardy Pink' in the control and EP1 in the drought. EP2 in the drought tended to have the highest SLM, but no differences were found among EP2, EP1, and 'Hardy Pink' in the drought. Again, 'Hardy Pink' and 'Hardy Red' in the drought had similar SLM; EP2 and 'Hardy Pink' in the control and 'Hardy Red' in the drought had similar SLM. 'Hardy Red' in the control had the lowest SLM, but there was no difference between EP1 and 'Hardy Red' in the control.

No interactions between drought treatment and clone were found on root DW, root-to-shoot ratio, leaf width, and leaf length (Table 1; Fig. 3). Root DW was not influenced by drought treatment. Root DW was highest in EP1, followed by EP2 and 'Hardy Pink' and 'Hardy Red'. Plants had a higher root-to-shoot ratio under drought stress. Root-to-shoot ratio was higher in EP2 than that in other clones. There were no differences in the root-to-shoot ratio between EP1 and 'Hardy Red' or between 'Hardy Pink' and 'Hardy Red'. Drought stress reduced leaf width and length. 'Hardy Pink' had smaller leaf width than other clones. EP1 had the longest leaves, followed by EP2, 'Hardy Red', and 'Hardy Pink'.

LEAF-WATER RELATIONS. When the substrate moisture content decreased from $20 \%$ to $\approx 8 \%$, predawn water potential decreased in all clones (Fig. 4). Rapid decreases in leaf water potentials started around $15 \%$, and the sharpest decreases occurred around $10 \%$ in all clones. The predawn water potentials at $10 \% \pm 1 \%$ for the majority were between $-2 \mathrm{MPa}$ and -3 MPa for EP1 and between -1 MPa to -2 MPa for the others.

Leaf gas EXChange. As substrate moisture content decreased, $P_{n}, E$, and $g_{s}$ for EP1 and 'Hardy Red' and $P_{n}$ of 'Hardy Pink' decreased quadratically (Fig. 5). In the range of substrate moisture contents below $30 \%, \mathrm{P}_{\mathrm{n}}, \mathrm{E}$, and $\mathrm{g}_{\mathrm{s}}$ generally decreased linearly for all clones. The $\mathrm{CO}_{2}$ concentration inside the leaf was unaffected by substrate moisture levels regardless of clone (data not shown). For all clones, $\mathrm{P}_{\mathrm{n}}$ was highly correlated with $g_{\mathrm{s}}$ (Fig. 6; $P<0.0001$ ). However, the response is nonlinear with a leveling trend in $P_{n}$ at high $g_{s}$, suggesting that reductions in $g_{s}$ at high $g_{s}$ may not inhibit $P_{n}$. The initial slopes at $\mathrm{g}_{\mathrm{s}}$ of zero were similar among the clones.

Light CuRve. $\mathrm{P}_{\mathrm{n}}$ in EP2, 'Hardy Pink', and 'Hardy Red' tended to saturate in the range of 1000 to $1500 \mu \mathrm{mol} \cdot \mathrm{m}^{-2} \cdot \mathrm{s}^{-1}$, in EP1 $\mathrm{P}_{\mathrm{n}}$ seemed to saturate at a slightly lower $P P F$ of 750 to $1000 \mu \mathrm{mol} \cdot \mathrm{m}^{-2} \cdot \mathrm{s}^{-1}$ (data not shown). Also, EP1 had the lowest $\mathrm{P}_{\mathrm{m}}$, EP2 and 'Hardy Pink' had the highest $\mathrm{P}_{\mathrm{m}}$, and no differences existed between EP1 and 'Hardy Red' or among EP2, 'Hardy Pink', and 'Hardy Red' (Table 2).

Chlorophyll fluorescence. On days 6 and 7 after withholding irrigation, an increase in $\mathrm{F}_{0}$, a decrease in $\mathrm{F}_{\mathrm{m}}$ on day 5 , and a decrease on day 6 in $F_{v} / F_{m}$ were observed in EP1 in the drought-treated plants compared with the control (Fig. 7). In $\mathrm{EP} 2$, an increase in $\mathrm{F}_{0}$ on day 6 and a decrease on day 5 in $\mathrm{F}_{\mathrm{m}}$, but no difference in $\mathrm{F}_{\mathrm{v}} / \mathrm{F}_{\mathrm{m}}$ were observed between the two treatments. In general, there were no differences in chlorophyll

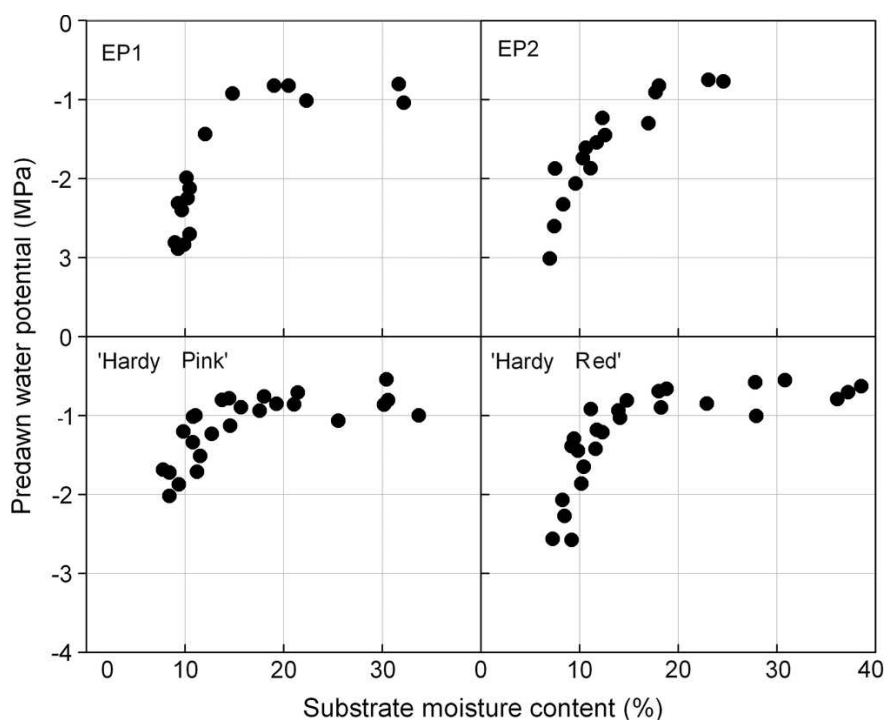

Fig. 4. Relationship between substrate moisture content and predawn leaf water potential during the severe dry stress period in EP1, EP2, 'Hardy Pink', and 'Hardy Red' of Nerium oleander. 

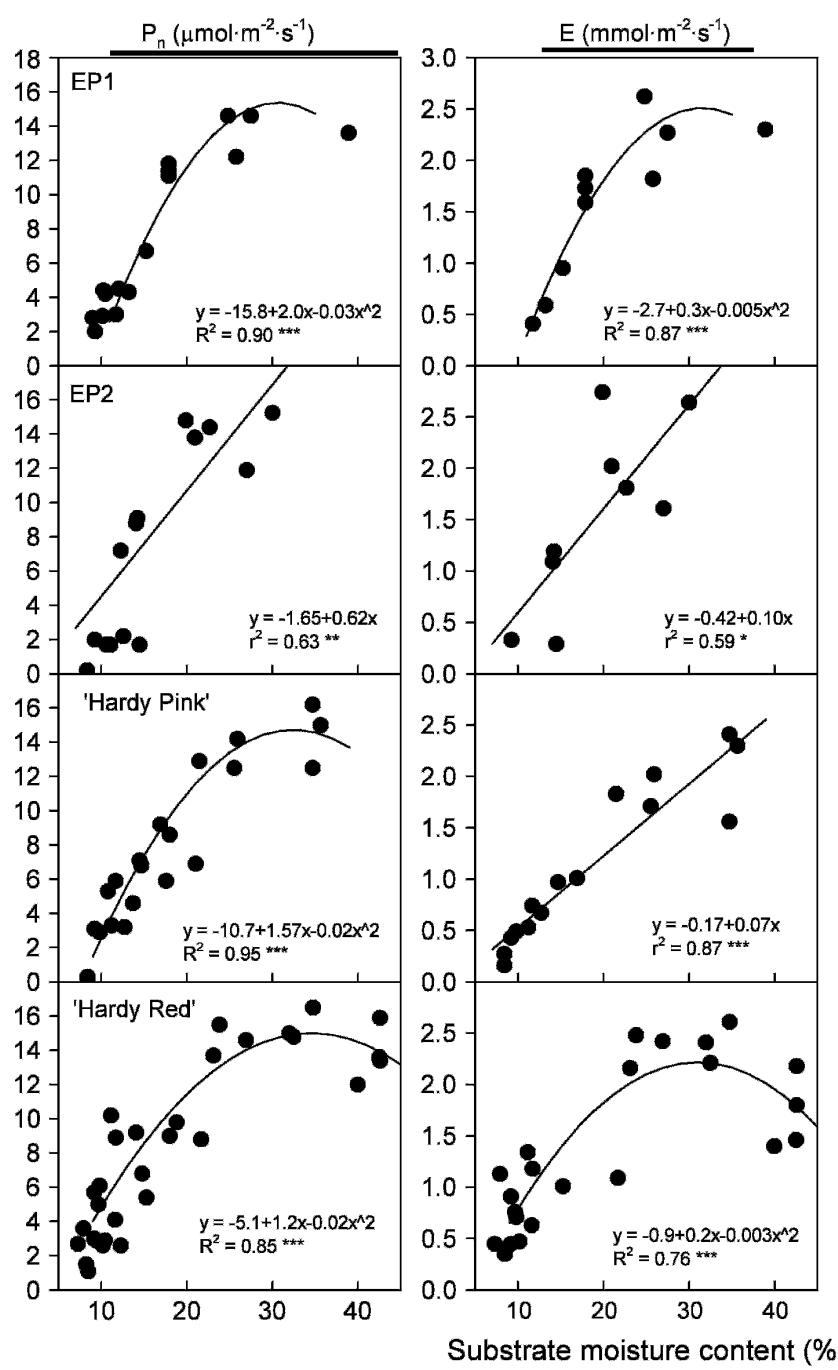

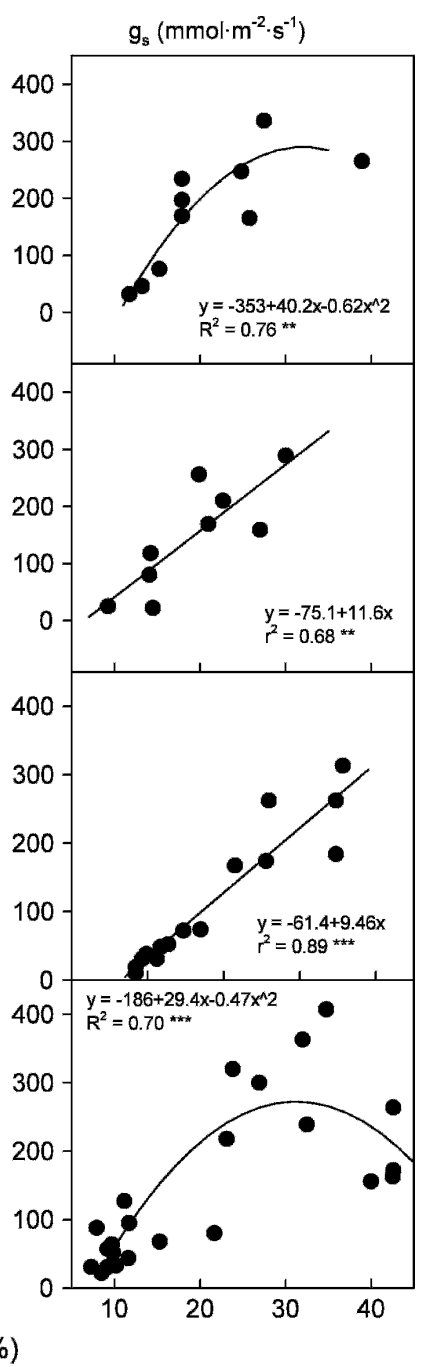

Fig. 5. Effect of substrate moisture content on leaf net photosynthetic rate $\left(\mathrm{P}_{\mathrm{n}}\right)$, transpiration $(\mathrm{E})$, and $g_{\mathrm{S}}\left(\mathrm{g}_{\mathrm{s}}\right)$ during the severe drought stress period of EP1, EP2, 'Hardy Pink', and 'Hardy Red' of Nerium oleander. In each graph, $*^{* * *}$, and $* * *$ indicate significance of the linear or quadratic regression at $P=0.05,0.01$, or 0.001 , respectively. fluorescence parameters in 'Hardy Pink' between the two treatments except a decrease in $F_{m}$ on day 5 in the drought-stressed plants. For 'Hardy Red', in addition to a decrease in $\mathrm{F}_{\mathrm{m}}$ on day $5, \mathrm{~F}_{\mathrm{v}} / \mathrm{F}_{\mathrm{m}}$ was lower on days 5 and 8 in the drought than the control plants. There were no differences in all chlorophyll fluorescence values in the diurnal course regardless of clone (data not shown).

\section{Discussion}

Drought stress reduced shoot DW, shoot elongation, and leaf size, and increased root-to-shoot ratio and SLM in all clones. However, the magnitude of these differences varied among the clones. An increased root-to-shoot ratio has been frequently observed in plants under drought conditions (Blum, 1996; Zwack and Graves, 1998). This increase was mostly from a larger reduction in shoot growth than in roots by water deficit. For example, the reductions in shoot DW in EP1 and EP2 were larger than those in 'Hardy Pink' and 'Hardy Red.' Therefore, the rootto-shoot ratios in the droughtstressed plants were higher in EP1 and EP2. The increased ratio of rootto-shoot implies the development of larger ratio of root length density to leaf area, which translates into a better capacity for sustaining drought stress (Blum, 1996). The high rootto-shoot ratio may help the survival of EP1 and EP2 under nonirrigated field conditions in the semiarid environment. Field soil moisture contents generally increase with soil depth, therefore, an extensive root system is able to access a larger soil volume to extract available water.

An increased SLM could represent an effective droughtresistance mechanism because it could allow photosynthesis to increase without a concomitant increase in leaf area and stomate number (Zwack and Graves, 1998). EP2 and 'Hardy Pink' in the drought treatment had higher SLM than EP1 and 'Hardy Red'. Also, EP2 adapted to drought stress by minimizing shoot growth (elongation and development). Droughttolerant plants should maintain a relatively high growth rate and productivity under drought conditions through mechanisms such as a reduction of water loss, increased extraction of water from the soil or substrate, and increased ability to tolerate low tissue water potential (Ngugi et al., 2004). Maintaining developmental rates during drought conditions is another criterion for assessing drought tolerance among genotypes (Blum, 1996). Drought stress often delays developmental events because of the inhibition of growth by water deficit. For example, the rate of new branching and that of leaf appearance in grapevine (Vitis vinifera L.) were inhibited by soil water deficit (Lebon et al.,

Fig. 6. Relationship between leaf net photosynthetic rate $\left(\mathrm{P}_{\mathrm{n}}\right)$ and $g_{\mathrm{S}}\left(\mathrm{g}_{\mathrm{s}}\right)$ during the severe drought stress period of EP1, EP2, 'Hardy Pink', and 'Hardy Red' of Nerium oleander.

\footnotetext{
.
} 
Table 2. Estimated parameters of the light curves for four clones of EP1, EP2, 'Hardy Pink', and 'Hardy Red' of Nerium oleander. $\mathrm{P}_{\mathrm{m}}=$ the maximum $\mathrm{P}_{\mathrm{n}}\left(\mu \mathrm{mol} \cdot \mathrm{m}^{-2} \cdot \mathrm{s}^{-1}\right) ; \mathrm{k}_{1}=$ a parameter related to the gradient of the $\mathrm{P}_{\mathrm{n}}$ versus $P P F$ curve at the light compensation point $\left(\mu \mathrm{mol}^{-1} \cdot \mathrm{m}^{2} \cdot \mathrm{s}\right) ; \mathrm{k}_{2}=$ the light compensation point $\left(\mu \mathrm{mol} \cdot \mathrm{m}^{-2} \cdot \mathrm{s}^{-1}\right)$.

\begin{tabular}{lccc}
\hline & \multicolumn{3}{c}{ Parameters } \\
\cline { 2 - 4 } Clone & $\begin{array}{c}\mathrm{P}_{\mathrm{m}} \\
\left(\mu \mathrm{mol} \cdot \mathrm{m}^{-2} \cdot \mathrm{s}^{-1}\right)\end{array}$ & $\begin{array}{c}\mathrm{k}_{1} \\
\left(\mu \mathrm{mol}^{-1} \cdot \mathrm{m}^{2} \cdot \mathrm{s}\right)\end{array}$ & $\begin{array}{c}\mathrm{k}_{2} \\
\left(\mu \mathrm{mol} \cdot \mathrm{m}^{-2} \cdot \mathrm{s}^{-1}\right)\end{array}$ \\
\hline EP1 & $11.1 \mathrm{~b}^{\mathrm{z}}$ & $0.00352 \mathrm{a}$ & $43.6 \mathrm{a}$ \\
EP2 & $17.0 \mathrm{a}$ & $0.00239 \mathrm{~b}$ & $45.9 \mathrm{a}$ \\
Hardy Pink & $15.7 \mathrm{a}$ & $0.00307 \mathrm{ab}$ & $46.0 \mathrm{a}$ \\
Hardy Red & $13.2 \mathrm{ab}$ & $0.00282 \mathrm{ab}$ & $42.9 \mathrm{a}$
\end{tabular}

${ }^{\mathrm{z}}$ Means within each column followed by the same letters are not significantly different among the clones tested by Student-NewmanKeuls multiple comparison at $P=0.05(\mathrm{n}=3)$.
Low predawn leaf water potentials reflect limited water availability to roots or an inefficient water conducting system (Zwack and Graves, 1998). We noticed that predawn leaf water potentials decreased rapidly with substrate moisture content after the moisture content decreased to a critical point. This critical substrate moisture content seemed to be around $15 \%$ for all clones. No substantial differences were observed among the clones in the relationship between predawn leaf water potential and the substrate moisture content (Fig. 4). Björkman et al. (1980) reported that midday leaf water potential ranged from -0.93 to $-3.2 \mathrm{MPa}$ for well-watered and water-stressed oleander plants grown in containers and $-6.7 \mathrm{MPa}$ for severely waterstressed plants grown in the field in Death Valley. We did not measure the midday leaf water potentials, which should be lower than the predawn water potentials on the same day. We found that predawn leaf water potentials recovered completely the next day after rewatering, regardless of severity of water stress for all clones (data not presented). Björkman et al. (1980) reported that rapid increases in leaf water potential of oleander were observed within hours after re-irrigation. Predawn needle water potentials of $P$. ponderosa genotypes were similar among various sources, regardless of their tolerance to drought stress (Cregg, 1994). Under field conditions, high predawn water potential was maintained in oaks (Quercus L.) with deeper root systems, as soil moisture content was higher in deeper soil (Abrams, 1990). Therefore, water potential is a parameter for quantifying the degree of water stress, but may not be a good indicator in quantifying water stress tolerance because of its high sensitivity to substrate or soil moisture contents and rapid recovery after rewatering.

Gas exchange $\left(\mathrm{P}_{\mathrm{n}}, \mathrm{E}\right.$, and $\left.\mathrm{g}_{\mathrm{s}}\right)$ responded similarly among the clones to decreases in substrate moisture contents. As substrate moisture content decreased to below $30 \%, g_{\mathrm{S}}$ and the rate of transpiration (E) started to decrease, suggesting that stomata started to close. When E was plotted against $g_{s}$, a linear relationship was obtained in all clones (data not shown), whereas the relationships between $P_{n}$ and $g_{s}$ were

Fig. 7. Chlorophyll fluorescence parameters, $F_{0}, F_{m}$, and $F_{v} / F_{m}\left(F_{v}=F_{m}-F_{0}\right)$, of EP1, EP2, 'Hardy Pink', and 'Hardy Red' of Nerium oleander measured during the severe drought stress period. Vertical bars represent standard errors. In each graph, $*$ and $* *$ indicate significance differences between the two treatments by $t$ test at $P=0.05$ or 0.01 .

2006). In this study, EP2 developed no new shoots, whereas 'Hardy Pink', 'Hardy Red', and EP1 developed 6.8, 3.0, and 0.7 new shoots, respectively. Therefore, in terms of productivity, 'Hardy Pink' was more tolerant than other clones because 'Hardy Pink' had least reduction in shoot and root growth and leaf area and had the largest shoot elongation. However, EP1 and EP2 may be more tolerant in terms of survival because of a high root-to-shoot ratio, which may mean a higher capacity to extract water from a larger or deeper soil profile under field conditions. curvilinear (Fig. 6). $P_{n}$ did not decrease substantially with $g_{s}$ at high $\mathrm{g}_{\mathrm{s}}$, suggesting that the impact of initial stomatal closure was larger on $\mathrm{E}$ than $\mathrm{P}_{\mathrm{n}}$. The light curves of the control plants indicated that EP1 had slightly low $\mathrm{P}_{\mathrm{m}}$ compared with other clones (Table 2). However, EP1 had the largest leaf area, which may compensate for a low $\mathrm{P}_{\mathrm{m}}$. A high $\mathrm{P}_{\mathrm{m}}$ indicates high potential of photosynthetic rate. Similar gas exchange rates in needles of $P$. ponderosa among the most and least drought-tolerant genotypes under drought conditions were observed (Cregg, 1994). 
Chlorophyll fluorescence is an indicator of PSII functioning and electron transfer from PSII to PSI and has been used frequently to estimate damage to the photosynthetic system. We observed increases in $F_{0}$ and decreases in $F_{m}$ and $F_{v} / F_{m}$ in the drought-stressed plants in all clones, although the magnitudes were small and not consistent throughout the dry-down period. Photochemical damage is reflected in an increase in $\mathrm{F}_{0}$ or decreases in $\mathrm{F}_{\mathrm{m}}$ or $\mathrm{F}_{\mathrm{v}} / \mathrm{F}_{\mathrm{m}}$ (Thomas and Turner, 2001). Percival and Sheriffs (2002) reported that $\mathrm{F}_{0}$ was a more effective indicator of drought stress than $\mathrm{F}_{\mathrm{v}} / \mathrm{F}_{\mathrm{m}}$. In this study, EP1 tended to exhibit a consistently higher $F_{0}$ in the drought treatment (Fig. 7). These relatively small alterations in $F_{0}, F_{m}$, and $\mathrm{F}_{\mathrm{v}} / \mathrm{F}_{\mathrm{m}}$ may indicate that the drought stress was not severe enough to damage the photosynthetic apparatus. Drought stress did not alter the $F_{\mathrm{v}} / \mathrm{F}_{\mathrm{m}}$ in bigtooth maples (Bsoul et al., 2006) and papaya (Marler and Mickelbart, 1998). However, a reduction in $\mathrm{F}_{\mathrm{m}}$ of sunlit leaves but not in shaded leaves of oleander was reported (Bjorkman and Powles, 1984), which may be caused by high light levels. In our study, plants were grown in the greenhouse and the maximum $P P F$ was between 600 to $800 \mu \mathrm{mol} \cdot \mathrm{m}^{-2} \cdot \mathrm{s}^{-1}$. Significant decreases in $\mathrm{F}_{\mathrm{v}} / \mathrm{F}_{\mathrm{m}}$ during midday were observed on a number of bedding plants grown outdoors (Niu et al., 2006), possibly from intense solar radiation or high temperatures. We observed that all chlorophyll fluorescence parameters on a sunny day inside the greenhouse were in the right range. No midday reductions in $F_{m}$ or $F_{v} / F_{m}$ or increases in $F_{0}$ were observed in control or drought plants.

In summary, the growth of all clones responded to drought stress differently: EP2 had the highest root-to-shoot ratio and the least shoot growth and development; EP1 had a lower ratio of root-to-shoot and maintained greater shoot growth and development than EP2. 'Hardy Pink' had the largest shoot growth and development with smallest leaves. No substantial differences were observed among the clones in their physiological responses to drought stress. Therefore, we concluded that 'Hardy Pink' may be more tolerant, followed by 'Hardy Red' in terms of productivity. However, EP2 and EP1 may be more tolerant to drought when survival is concerned because they had larger root-to-shoot ratios.

\section{Literature Cited}

Abrams, M.D. 1990. Adaptations and responses to drought in Quercus species of North America. Tree Physiol. 7:227-238.

Björkman, O., W.J.S. Downton, and H.A. Mooney. 1980. Response and adaptation to water stress in Nerium oleander. Carnegie Institution, Washington Year Book 79:150-157.

Bjorkman, O. and S.B. Powles. 1984. Inhibition of photosynthetic reactions under water stress: Interaction with light level. Planta 161:490-504.

Blum, A. 1996. Crop responses to drought and the interpretation of adaptation. Plant Growth Regul. 20:135-148.

Bsoul, E., R. St. Hilaire, and D.M. VanLeeuwen. 2006. Bigtooth maples exposed to asynchronous cyclic irrigation show provenance differences in drought adaptation mechanisms. J. Amer. Soc. Hort. Sci. 131:459-468.

Cregg, B. 1994. Carbon allocation, gas exchange, and needle morphology of Pinus ponderosa genotypes known to differ in growth and survival under imposed drought. Tree Physiol. 14:883-898.

Cregg, B. 2004. Improving drought tolerance of trees: Theoretical and practical considerations. Acta Hort. 630:147-158.

Cregg, B. and J.W. Zhang. 2001. Physiology and morphology of Pinus sylvestris seed sources from diverse sources under cyclic drought stress. For. Ecol. Manage. 154:131-139.

Dirr, M.A. 1998. Manual of woody landscape plants. Stipes, Champaign, IL.
Fernández, J.A., L. Balenzategui, S. Banón, and J.A. Franco. 2006. Induction of drought tolerance by paclobutrazol and irrigation deficit in Phillyrea angustifolia during the nursery period. Scientia Hort. 107:277-283.

Gollan, T., N.C. Turner, and E.D. Schulze. 1985. The responses of stomata and leaf gas exchange to vapor pressure deficits and soil water content. III. In the sclerophyllous woody species Nerium oleander. Oecologia 65:356-362.

Hagidimitriou, M. and C.A. Pontikis. 2005. Seasonal changes in $\mathrm{CO}_{2}$ assimilation in leaves of five major Greek olive cultivars. Scientia Hort. 104:11-24.

Hsiao, T.C. and E. Acevedo. 1974. Plant responses to water deficits, water use efficiency, and drought resistance. Agr. For. Meteorol. 14:59-84.

Huang, B. 2004. Recent advances in drought and heat stress physiology of turfgrass: A review. Acta Hort. 661:185-192.

Lebon, E., A. Pellegrino, G. Louarn, and J. Lecoeur. 2006. Branch development controls leaf area dynamics in grapevine (Vitis vinifera) growing in drying soil. Ann. Bot. (Lond.) 98:175-185.

Mackay, W.A., M.A. Arnold, and J.M. Parsons. 2005. Nerium oleander L. 'Cranberry Cooler', 'Grenadine Glace', 'Pink Lemonade', 'Peppermint Parfait', 'Raspberry Sherbet', and 'Petite Peaches and Cream'. HortScience 40:265-268.

Marler, T.E. and M.V. Mickelbart. 1998. Drought, leaf gas exchange, and chlorophyll fluorescence of field-grown papaya. J. Amer. Soc. Hort. Sci. 123:714-718.

Ngugi, M.R., D. Doley, and M.A. Hunt. 2004. Physiological responses to water stress in Eucalyptus cloeziana and E. argophloia seedlings. Trees (Berl.) 18:381-389.

Niu, G., T. Kozai, and Y. Kitaya. 1996. Simulation of the time courses of $\mathrm{CO}_{2}$ concentration in the culture vessel and net photosynthetic rate of Cymbidium plantlets. Trans. Amer. Soc. Agr. Eng. 39:1567-1573.

Niu, G., D. Rodriguez, and Y.T. Wang. 2006. Impact of drought and temperature on growth and leaf gas exchange of six bedding plant species under greenhouse conditions. HortScience 41:1408-1411.

Percival, G.C. and C.N. Sheriffs. 2002. Identification of droughttolerant woody perennials using chlorophyll fluorescence. J. Arboriculture 28:215-223.

Ranney, T.G., F.A. Blazich, and S.L. Warren. 1995. Heat tolerance of selected species and populations of rhododendron. J. Amer. Soc. Hort. Sci. 120:423-428.

Ranney, T.G. and J.M. Ruter. 1997. Foliar heat tolerance of three holly species (Ilex spp.): Responses of chlorophyll fluorescence and leaf gas exchange to supraoptimal leaf temperatures. J. Amer. Soc. Hort. Sci. 122:499-503.

Stafne, E.T., J.R. Clark, and C.R. Rom. 2000. Leaf gas exchange characteristics of red raspberry germplasm in a hot environment. HortScience 35:278-280.

Starman, T. and L. Lombardini. 2006. Growth, gas exchange, and chlorophyll fluorescence of four ornamental herbaceous perennials during water deficit conditions. J. Amer. Soc. Hort. Sci. 131:469-475.

St. Hilaire, R. and W.R. Graves. 2001. Stability of provenance differences during development of hard maple seedlings irrigated at two frequencies. HortScience 36:654-657.

Tezara, W., V.J. Mitchell, S.D. Driscoll, and D.W. Lawlor. 1999. Water stress inhibits plant photosynthesis by decreasing coupling factor and ATP. Nature 401:914-917.

Thomas, D.S. and D.W. Turner. 2001. Banana (Musa sp.) leaf gas exchange and chlorophyll fluorescence in response to soil drought, shading and lamina folding. Scientia Hort. 90:93-108.

Tipton, J.L. and M. White. 1995. Differences in leaf cuticle structure and efficacy among eastern redbud and Mexican redbud phenotypes. J. Amer. Soc. Hort. Sci. 120:59-64.

Willits, D.H. and M.M. Peet. 2001. Measurement of chlorophyll fluorescence as a heat stress indicator in tomato: Laboratory and greenhouse comparisons. J. Amer. Soc. Hort. Sci. 126:188-194.

Zwack, J.A. and W.R. Graves. 1998. Leaf water relations and plant development of three freeman maple cultivars subjected to drought. J. Amer. Soc. Hort. Sci. 123:371-375. 